\title{
Conversion of waste plastics into low-emissive hydrocarbon fuels through catalytic depolymerization in a new laboratory scale batch reactor
}

\author{
P. Senthil Kumar • M. Bharathikumar • \\ C. Prabhakaran $\cdot$ S. Vijayan $\cdot$ K. Ramakrishnan
}

Received: 31 October 2014/Accepted: 12 February 2015/Published online: 25 February 2015

(c) The Author(s) 2015. This article is published with open access at Springerlink.com

\begin{abstract}
Pyrolysis of waste plastic is a prospective way of conversion of waste plastic into low-emissive hydrocarbon fuel. The present research is focused on the conversion of waste plastic into low-emissive hydrocarbon fuel by two process namely vacuum and catalytic cracking (activated carbon, activated carbon with granulated charcoal and activated carbon with calcium oxide). Waste plastic materials viz., polyethylene, polypropylene, polystyrene and polyethylene terephthalate were collected from local convenience store packing materials. Waste plastic material pyrolysis was conducted as individual plastics and as mixed feed in a new laboratory scale batch reactor. Hydrocarbon molecules from the basic materials are split under the impact of catalyst inside the reactor in $70-240{ }^{\circ} \mathrm{C}$. The reduction of process takes place from $500-600{ }^{\circ} \mathrm{C}$ to $240{ }^{\circ} \mathrm{C}$ in the presence of catalyst. The analyses of pyrolysis products suggested that it can be used as a viable alternative to motor fuel. It was observed that the yield was better in the case of individual plastic material as opposed to mixed feed in all cases except polypropylene under non-catalysed vacuum process. The comparison of the GC-FID (TPH) report of the obtained oil
\end{abstract}

Published in the Special Issue "Energy, Environment, Economics and Thermodynamics".

\footnotetext{
P. Senthil Kumar $(\bowtie) \cdot$ M. Bharathikumar · C. Prabhakaran

K. Ramakrishnan

Department of Chemical Engineering, SSN College of

Engineering, Chennai 603 110, India

e-mail: senthilchem8582@gmail.com

S. Vijayan

Department of Mechanical Engineering, SSN College of Engineering, Chennai 603 110, India
}

with that of the commercial petrol clearly proves that the prepared oil is composed of petrol components.

Keywords Waste plastics - Pyrolysis - Alternative fuel · Catalytic conversion · Hydrocarbon · Petrol

\section{Introduction}

Due to the erratic change of energy prices and unfavourable forecast of world economy, considerable efforts have been devoted to substitute raw fossil fuels with various other sources for the production of energy. The various factors, such as ever increasing diesel consumption, large outflow of foreign exchange, and concern for environment, contribute to the search for a suitable environmental friendly alternative to fossil fuel. It is clearly envisaged that the increasing GDP and the limits of greenhouse gases can only be compensated by the application of waste recycling process (e.g., plastic, paper, metals, etc.) $[1,2]$. The plastics have become one of the most important and indispensable materials in our contemporary world. These plastics are not presently biodegradable and are extremely troublesome components for land filling. The waste plastics are known for creating a very serious environmental challenge because of their huge quantities and the disposal problems caused by them [3]. To avoid the impact of the plastic in the environment, the recycling of plastics constitutes a valid alternative. Primarily, mechanical reprocessing is the method of plastic recycling which is the feasible only when high purity selectively collected wastes are available [4]. Alternatively, there is an attractive process for recycling by thermal or catalytic method which produces hydrocarbon. The pyrolysis can be cost effective compared to other processes. 
The pyrolysis thermally degrades the plastic component to produce an oil and gas product. This oil may be used as a liquid fuel or returned for refining $[5,6]$.

The pyrolysis has a wide temperature range and it can be performed with or without a catalyst. Generally used catalysts for this process are mordenite, FCC, USY, ZSM-5, etc. However, the addition of catalyst can be troublesome as the catalyst might get accumulated in the residue or coke [7-18]. Hence an alternative catalyst has to be introduced in the process, which must bring about a reduction in the energy consumption and an increase in the yield. Much research has been conducted on thermal cracking studies on polyethylene [20], polystyrene [21], and polypropylene [22] as individual feedstock for the pyrolysis process. On the other hand, only a few have worked on the thermal decomposition of the mixed feedstock containing polyethylene, polypropylene and polystyrene [19].

The aim of the present research is to investigate the waste plastic pyrolysis in the presence and absence of the catalysts such as activated carbon or calcium oxide to produce very low-emissive liquid hydrocarbon oil. The amount of waste plastic residue has to be reduced, with an increase in the efficiency of the fuel oils, thus providing an alternate energy resource to the environment. This would bring about a major reduction in the pollution caused due to landfills of plastic wastes and air pollution through the incineration of plastics.

\section{Experimental}

\section{Materials}

The waste plastics were collected from the various places across the neighbourhood. Namely, high-density polyethylene (HDPE) was collected in the form of garbage containers, low-density polyethylene (LDPE) as used lowgrade plastic bags, polystyrene (PS) in the form of disposable cutlery, polypropylene (PP) as used waste plastic containers, and polyethylene terephthalate (PET) as used plastic bottles. The melt flow index (MFI) and the density of the raw materials are listed in Table 1. The waste plastic materials were shredded and thoroughly washed with tap water. This helps to increase the surface area of material in contact with catalyst during pyrolysis.

Catalyst

The catalyst influences not only the structure of the products, but also their yield. Hence the results of pyrolysis in the absence of catalyst were compared with results obtained by pyrolysis which was carried out in the presence of the catalyst viz. activated carbon, granulated charcoal and calcium oxide. Due to its high degree of micro porosity, just one gram of activated carbon has a surface area in excess of $500 \mathrm{~m}^{2} / \mathrm{g}$, as determined by nitrogen gas adsorption. Activated carbon was obtained from Merck, India. Granulated charcoal was produced from wood. Calcium oxide laboratory chemical was obtained from Qualigens Chemicals, India.

\section{Pyrolysis process}

The pyrolysis process is an advanced conversion technology that has the ability to produce a clean, high-calorific value fuel from a wide variety of biomass and waste streams. It is the thermo-chemical decomposition of organic material at elevated temperatures in the absence of oxygen. The pyrolysis provides various operational, environmental and economical advantages. Under pressure and heat, the long chain polymers of hydrogen, oxygen, and carbon decompose into short-chain petroleum hydrocarbons with a ceiling length of around 18 carbons. Hydrocarbon molecules from the basic materials are split under the impact of the catalytic (carbon material) convertor inside the reactor at $70-240{ }^{\circ} \mathrm{C}$. The reduction of process temperature takes place from $500-600{ }^{\circ} \mathrm{C}$ to $240{ }^{\circ} \mathrm{C}$. The higher yield of liquid fuel of about $98 \%$ was achieved.

\section{Distillation}

The distillation is a method of separating mixtures based on differences in their volatilities. The collected oil from pyrolysis process was found to contain various percentages of gases and various densities of oil. The presence of the catalyst has enhanced the medium to reflux and then
Table 1 Melt flow index and the density of the raw materials

\begin{tabular}{llll}
\hline Waste polyolefin & Source & MFI (g/10 min) & Density \\
\hline Polystyrene & Disposable cutlery & 8.0 & 0.961 \\
Polypropylene & Plastic containers & 40.0 & 0.905 \\
High-density polyethylene & Garbage containers & 7.1 & 0.965 \\
Low-density polyethylene & Plastic bags & 70 & 0.910 \\
Polyethylene terephthalate & Plastic bottles & 8.5 & 1.38 \\
\hline
\end{tabular}


distilled to obtain three fractions viz. gas, light oil, and heavy oil.

\section{Regeneration of spent catalyst}

The spent catalyst was first dissolved in some amount of water and heated to around $80{ }^{\circ} \mathrm{C}$. The residue material was separated using Whatman no. 40 filter paper. The catalyst was then dried to about $80{ }^{\circ} \mathrm{C}$ using a heating oven. The regenerated catalyst was used for another batch operation.

\section{Experimental setup}

A wide range of reactors have been used on a laboratory scale for the plastic pyrolysis process. The reactor set-up in this research is a batch reactor. A common variant between the batch and semi-batch operations is the vacuum, which causes the reduction of temperature of the reaction to take place inside the Borosil round bottom flask. The two types of feed patterns were used, namely individual types of plastics and mixed types of plastics. The composition of the individual and mixed plastic wastes is given in Tables 2, 3, 4, 5 and 6.

The pre-processed waste plastic materials were transferred into an empty round bottom borosil glass flask of capacity $1000 \mathrm{~mL}$. The empty weight of round bottom flask was found to be $343.12 \mathrm{~g}$. After the raw materials were loaded into the round bottomed flask, the opening was connected to a condenser and the condenser was connected to a receiving adapter. The round bottom flask is fixed with heating mantle. The oil is collected at the bottom end. During the whole process, the temperature was maintained around 30 to $240{ }^{\circ} \mathrm{C}$ and a vacuum pressure of about $300 \mathrm{~mm} \mathrm{Hg}$ maintained. A vacuum pump was used to create vacuum inside the round bottom flask. The temperature was raised according to the gradient. The experimental setup is shown in Fig. 1. The condensed oil was collected in the oil collector. The melting points of the various feed types with and without the catalysts are summarized in the Table 7. The collected oil was refluxed and further distilled. After distillation process, three types of fractions were obtained from the present research. The whole process of pyrolysis took place under $45 \mathrm{~min}$ to complete.

Table 2 Individual plastic for non-catalytic degradation process

\begin{tabular}{ll}
\hline Individual plastic materials & Weight in grams \\
\hline Polyethylene & 11.3 \\
Polystyrene & 15 \\
Polypropylene & 20.052 \\
\hline
\end{tabular}

Table 3 Mixed plastics for non-catalytic degradation process

\begin{tabular}{ll}
\hline Mixed plastic composition & Weight in grams \\
\hline Polystyrene & 15.924 \\
Polypropylene & 15.312 \\
Polyethylene & 14.906 \\
\hline
\end{tabular}

Table 4 Mixed plastics catalytic degradation process (activated carbon)

\begin{tabular}{ll}
\hline Mixed plastic composition & Weight in grams \\
\hline Polystyrene & 15.122 \\
Polypropylene & 15.012 \\
Polyethylene & 16.552 \\
\hline
\end{tabular}

Table 5 Mixed plastic for catalytic degradation process (activated carbon + charcoal)

\begin{tabular}{ll}
\hline Mixed plastic composition & Weight in grams \\
\hline Polystyrene & 15.039 \\
Polypropylene & 15.021 \\
Polyethylene & 16.221 \\
\hline
\end{tabular}

Table 6 Mixed plastic for catalytic degradation process (activated carbon + calcium oxide)

\begin{tabular}{ll}
\hline Mixed plastic composition & Weight in grams \\
\hline Polystyrene & 15.2 \\
Polypropylene & 15.03 \\
Polyethylene & 15.884 \\
Polyethylene terephthalate & 15.68 \\
\hline
\end{tabular}

Analysis of products

The liquid products were analysed by gas chromatograph (TRACE GC) with a flame ionization detector. It was provided with a $50 \mathrm{~m} \times 0.32 \mathrm{~mm} \mathrm{Rtx}{ }^{\circledR}-1$ (Cross bond $100 \%$ Dimethyl-polysiloxane) column. To further narrow down the qualitative analysis, a GC-FID total petroleum hydrocarbons (TPH) was also used. Each fraction was also subjected to a separate analysis viz. flash point, fire point and density. The results observed for the prepared oil were compared with the GC-FID report of commercial petrol. The effect of temperature depends on the increase in the time taken for the pyrolysis process (see Fig. 2).

\section{Results and discussion}

The overall conversion and residue, along with the various other parameters such as temperature maintained, applied 


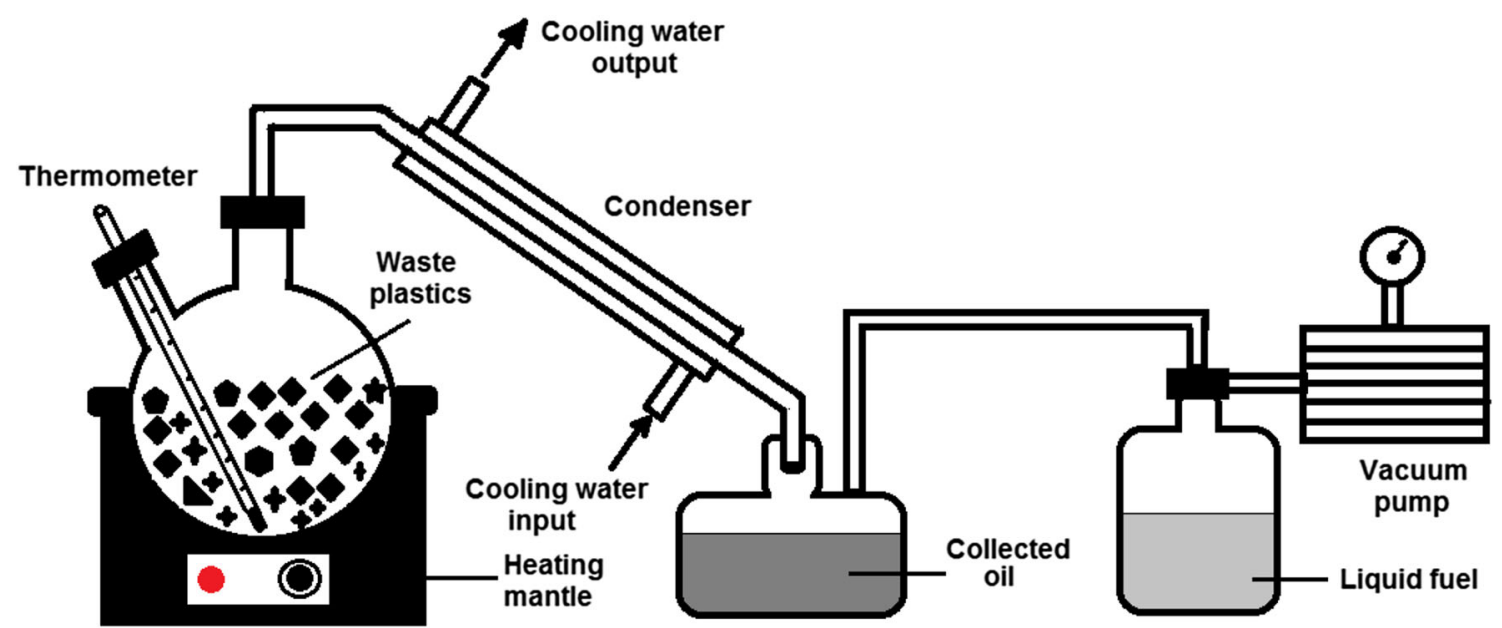

Fig. 1 Experimental setup

Table 7 Melting point of the various plastics and various processes

\begin{tabular}{lll}
\hline Raw materials & Catalysts & Melting point $\left({ }^{\circ} \mathrm{C}\right)$ \\
\hline Polystyrene & Nil & 190 \\
Polypropylene & Nil & 120 \\
Polyethylene & Nil & 110 \\
Mixed plastic & Nil & 185 \\
Mixed plastics & Activated carbon & 75 \\
Mixed plastics & Activated carbon + charcoal & 75 \\
Mixed plastics & Activated carbon $+\mathrm{CaO}$ & 70
\end{tabular}

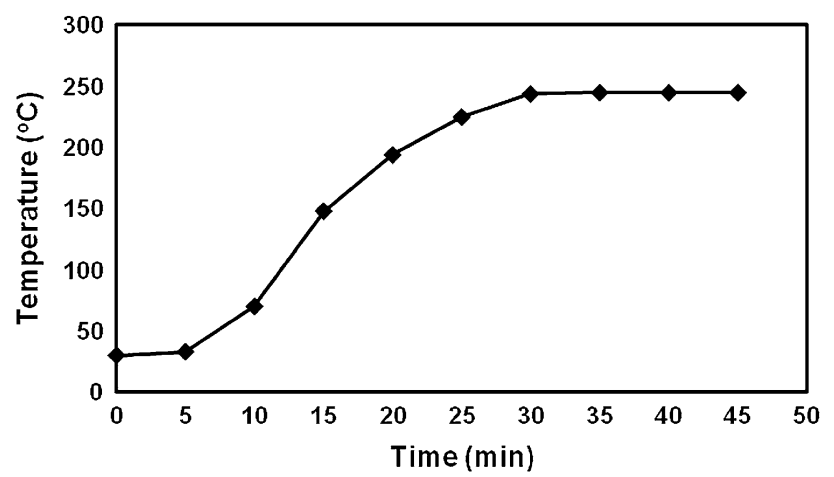

Fig. 2 Effect of contact time

vacuum pressure and the reaction time for the individual and mixed feed, are summarized in the Table 3. The various types of liquid hydrocarbon products were received from catalytic and non-catalytic cracking methods. The catalyst has influenced the yield and the composition of the liquid yield. The activity of charcoal has influenced the yield up to more than $95 \%$. The use of the calcium oxide along with the activated carbon was not proved to be much advantageous (see Table 8).
Physical properties of oil

\section{Specific gravity and density}

Hydrocarbons of low specific gravity can be calculated with the help of the ratio of maximum thermal energy to the volume of oil. The formula used for finding the specific gravity is given as:

Specific gravity $=\frac{\text { density of sample }}{\text { density of water }}$

A $10 \mathrm{~mL}$ specific gravity bottle was used to determine the specific gravity of the samples. $10 \mathrm{~mL}$ of the sample was pipette out into a pre-weighed bottle up to its brim. This gives the weight of the sample which when divided by 10 gives the specific gravity and hence the density of the sample can be found out. It was found to be having a specific gravity of 0.811 and a density of $811.7 \mathrm{~kg} / \mathrm{m}^{3}$.

\section{Flash point}

The flash point of a volatile material is the lowest temperature at which it can vaporize to form an ignitable mixture in air. The flash point is used to determine the (1) volatility of liquid fuels, (2) amount of low boiling fraction present in the liquid fuel, and (3) explosion hazards. The flash point of the sample was determined using Pensky Martens closed cup flash point test. About $30 \mathrm{~mL}$ of the sample was heated and stirred for every $1{ }^{\circ} \mathrm{C}$ rise in temperature. An ignition source is directed into the cup at regular intervals with intermittent stirring until a flash that spreads throughout the inside of the cup is seen. The corresponding temperature is known as the flash point and was found to be $65^{\circ} \mathrm{C}$. 
Table 8 Experimental results of the process with and without catalyst

\begin{tabular}{|c|c|c|c|c|c|c|}
\hline Plastic materials & Catalysts & $\begin{array}{l}\text { Yield to liquid } \\
\text { product }(\%)\end{array}$ & Residue (\%) & $\begin{array}{l}\text { Temperature } \\
\text { maintained }(\mathrm{C})\end{array}$ & $\begin{array}{l}\text { Vacuum pressure } \\
\text { applied }(\mathrm{mm} \mathrm{Hg})\end{array}$ & $\begin{array}{l}\text { Reaction } \\
\text { time (min) }\end{array}$ \\
\hline Polystyrene & No catalysts & 80 & 13.33 & 240 & -550 & 30 \\
\hline Polypropylene & No catalysts & 60.7 & 34.40 & 240 & -500 & 35 \\
\hline Polyethylene & No catalysts & 75 & 22.43 & 240 & -300 & 45 \\
\hline Mixed plastics (PE, PP, PS) & No catalysts & 66.86 & 25.85 & 240 & -350 & 45 \\
\hline Mixed plastics (PE, PP, PS) & Activated carbon & 82.43 & 15.22 & 240 & -300 & 45 \\
\hline Mixed plastics (PE, PP, PS) & Charcoal & 95.54 & 2.33 & 240 & -300 & 35 \\
\hline Mixed plastics (PE, PP, PS, PET) & $\mathrm{CaO}+$ activated carbon & 75.50 & 20.33 & 240 & -300 & 45 \\
\hline
\end{tabular}

Fig. 3 GC-FID (TPH) report for petrol, diesel and motor oil

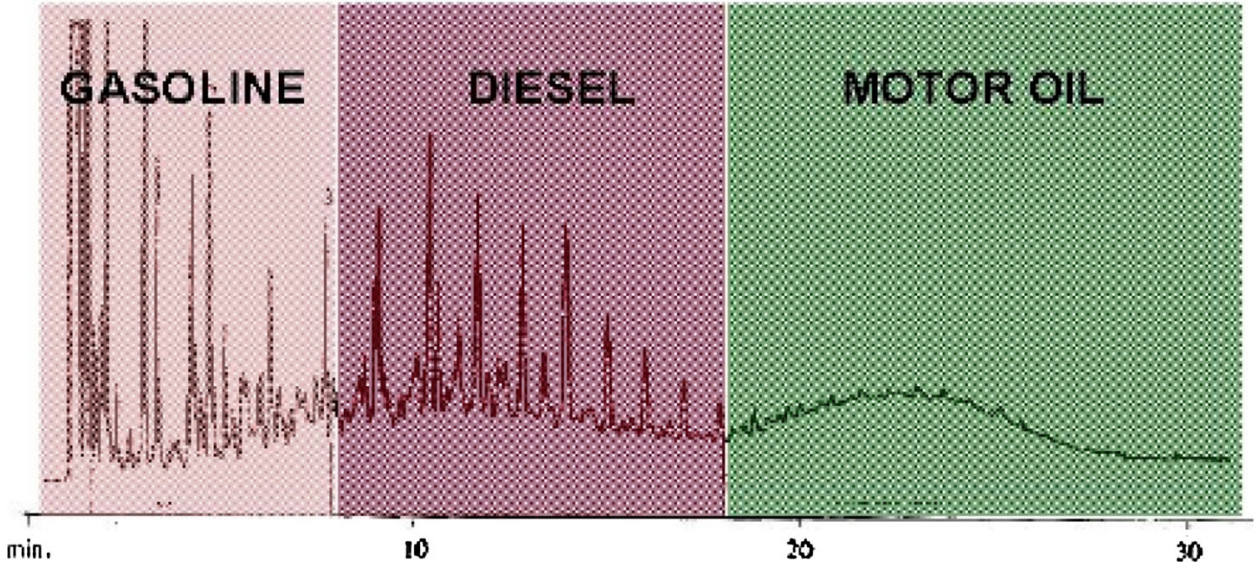

\section{Fire point}

It is the temperature at which the fuel will continue to burn for about $5 \mathrm{~s}$ after ignition by an open flame source. It is the temperature at which the vapour is produced to sustain a flame. The fire point was determined using the Pensky Martens open cup apparatus. About $30 \mathrm{~mL}$ of sample was heated and stirred continuously for every $1{ }^{\circ} \mathrm{C}$ rise in temperature. An ignition source was introduced into the cup at regular intervals until a flame sustains for at least $5 \mathrm{~s}$. The fire point of the light fraction oil sample was about $110^{\circ} \mathrm{C}$.

\section{Flame characteristics}

The flame characteristics of the light fraction oil were studied and this was compared with kerosene and petrol. It was observed that there were no carbon settlements on the tiles. This suggests that the oil from pyrolysis process has similar characteristics of petrol. Henceforth, the chemical properties of the light fraction oil were checked by the GCFID TPH analysis.

\section{Gas chromatography (GC-FID TPH analysis)}

Gas chromatography (GC) is the group of analytical separation techniques used to analyse volatile substances in the gas phase. Flame ionization detector (FID) is one of the most widely used detectors for GC. It has a wide field of application. For instance, the fuel for air planes, kerosene, is carefully analysed with GC-FID as a routine control. The overall complexity of the problem and of the spectrum of hydrocarbons is likely to be encountered. It is inevitable to view TPH as a single entity. This also relates to the sampling methodology employed. The approach consists of subdividing the hydrocarbon into the most volatile fraction (referred as gasoline range organics or GRO) and the less volatile less fraction. The GC-FID (TPH) for the petrol/ diesel/motor oil and commercial petrol is shown in Figs. 3 and $4 \mathrm{a}$, respectively.

The GC-FID (TPH) report for the oil, obtained as a result of pyrolysis, is shown in Fig. 4b. When the GC-FID (TPH) report of the obtained oil was compared with that of the commercial petrol, it was clearly evident that the prepared oil mainly consists of petrol components.

\section{Conclusion}

The current research process is technologically and economically viable for scaling up for industrial scale. There is no scarcity of feedstock as plastic waste generation has already become a habit of the modern society. 


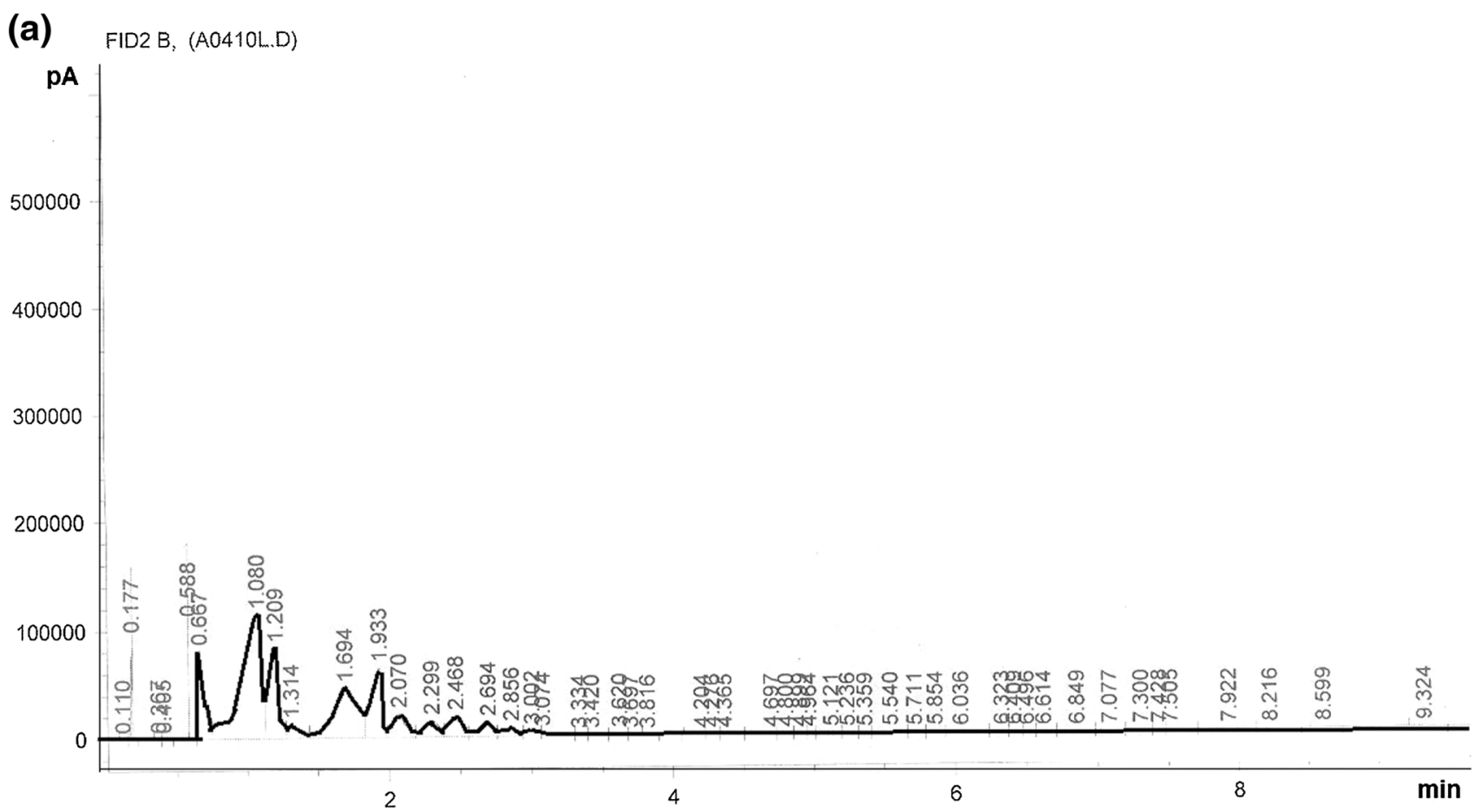

(b) FID2B, (A0410K.D)

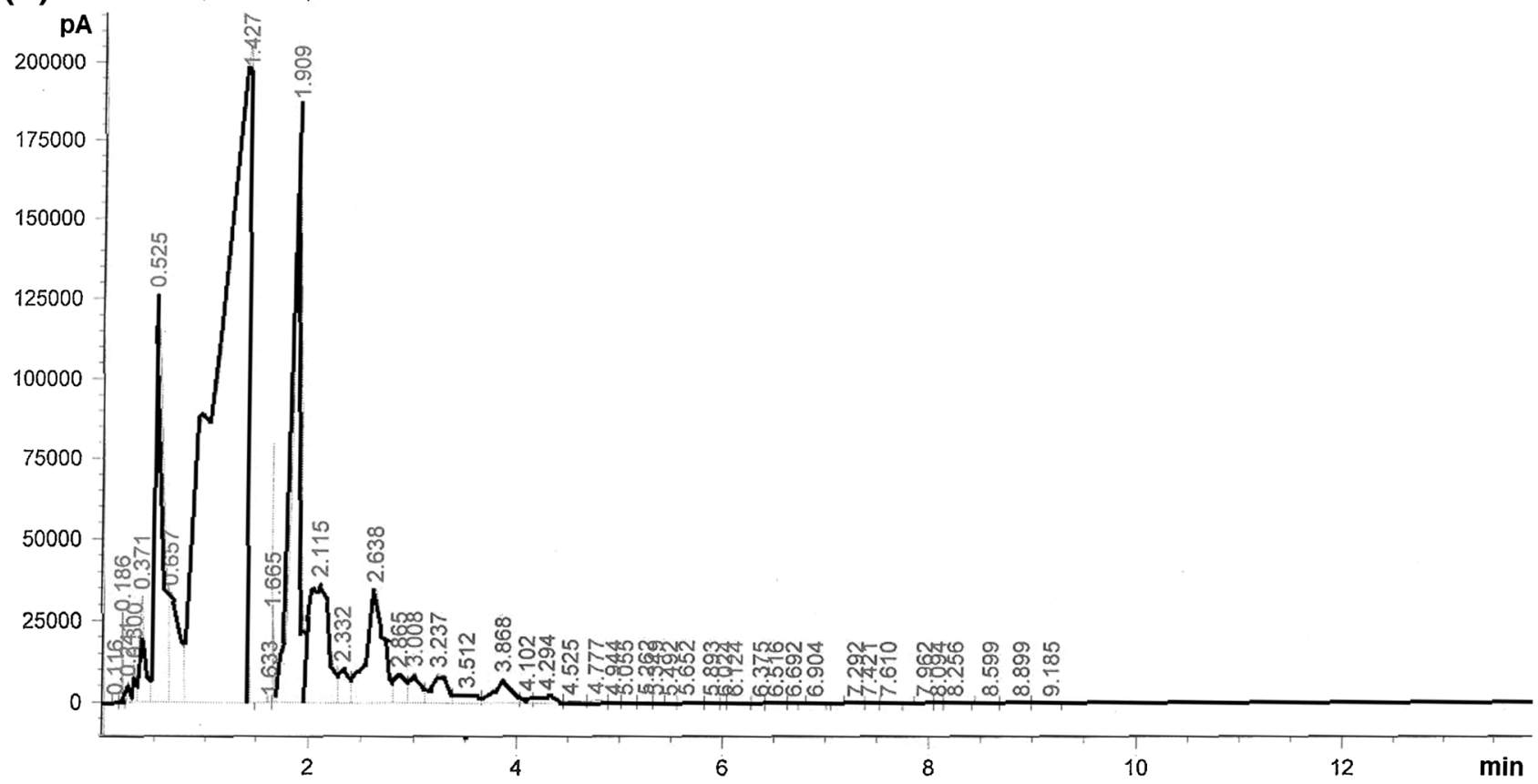

Fig. 4 a GC-FID(TPH) report for commercial petrol, b GC-FID(TPH) report for oil prepared from plastic wastes

- A simple catalytic and non-catalytic process for depolymerizing the waste plastics (individual and mixed plastics) to synthetic crude oil has been developed and further refined using a laboratory scale distillation followed by condensation process.
- The physical and chemical properties of the light fraction oil were done with the standard methods. The comparison of physical properties, chemical properties, and gas chromatograms suggests that the oil can be further fractionated and used as appropriate gasoline or aviation fuel. 
- The characterization studies by GC-FID indicate that the depolymerization product is essentially all straight chain hydrocarbons when linear thermoplastic polymers are used as feed. GC-FID analysis indicates that the prepared oil includes hydrocarbons ranging from $\mathrm{C}_{4}$ to $\mathrm{C}_{12}$, a range that includes commercial gasoline. $\mathrm{GC}$ FID analysis further indicates that the pyrolysed oil has higher percentage of petrol.

- The residue obtained from the distillation process can be used as lubricants for various types of equipment.

The present devised method may be an alternative method to recover higher amounts of oil from the waste plastic material.

Open Access This article is distributed under the terms of the Creative Commons Attribution License which permits any use, distribution, and reproduction in any medium, provided the original author(s) and the source are credited.

\section{References}

1. Miskolczi, N., Angyal, A., Bartha, L., Valkai, I.: Fuels by pyrolysis of waste plastics from agricultural and packaging sectors in a pilot scale reactor. Fuel Process Technol. 90, 1032-1040 (2009)

2. Mani, M., Nagarajan, G., Sampath, S.: Characterisation and effect of using waste plastic oil and diesel fuel blends in compression ignition engine. Energy 36, 212-219 (2011)

3. Siddiqui, M.N., Redhwi, H.H.: Catalytic coprocessing of waste plastics and petroleum residue into liquid fuel oils. J Anal Appl Pyrol 86, 141-147 (2009)

4. Passamonti, F.J., Sedran, U.: Recycling of waste plastics into fuels. LDPE conversion in FCC. Appl Catal B Environ 125, 499-506 (2012)

5. Sannita, E., Aliakbarian, B., Casazza, A.A., Perego, P., Busca, G.: Medium-temperature conversion of biomass and wastes into liquid products, a review. Renew Sustain Energy Rev 16, 6455-6475 (2012)

6. Torres, A., de Marco, I., Caballero, B.M., Laresgoiti, M.F., Legarreta, J.A., Cabrero, M.A., Gonzalez, A., Chomon, M.J., Gondra, K.: Recycling by pyrolysis of thermoset composites: characteristics of the liquid and gaseous fuels obtained. Fuel 79, 897-902 (2000)

7. Williams, P.T., Bagri, R.: Aromatic hydrocarbons from the catalytic pyrolysis of polypropylene plastic waste. Feedstock
Recycling of Plastics and Other Innovative Plastics Recycling Techniques ISFR' 2002, September, pp. 8-11, Ostend, Belgium (2002)

8. Kim, J.S., Lee, W.Y., Lee, S.B., Kim, S.B., Choi, M.J.: Degradation of polystyrene waste over base promoted Fe catalysts. Catal Today 87, 59-68 (2003)

9. Walendziewski, J., Steininger, M.: Thermal and catalytic conversion of waste polyolefines. Catal Today 65, 323-330 (2001)

10. Lee, S.Y., Yoon, J.H., Kim, J.R., Park, D.W.: Catalytic degradation of polystyrene over natural clinoptilolite Zeolite. Polym Deg Stab 74, 297-305 (2001)

11. Wddin, M.A., Koizumip, K., Murata, K., Sakata, Y.: Thermal structurally and catalytic degradation of different types of polyethylene into fuel oil. Polym Deg Stab 56, 37-44 (1997)

12. Madras, G., Kumar, S., Chattopadhyay, S.: Continuous distribution kinetics for ultrasonic degradation of polymers. Polym Deg Stab 69, 73-78 (2000)

13. Westphal, C., Perrot, C., Karlsson, S.: Py-GC/MS as a means to predict degree of degradation by giving microstructural changes modelled on LDPE and PLA. Polym Deg Stab 73, 281-287 (2001)

14. Koshiduka, T., Ohkawa, T., Takeda, K.: Computer simulation of thermal degradation of poly (butylene terephthalate) and analytical problems of terephthalic acid in scission products. Polym Deg Stab 79, 1-11 (2003)

15. Park, J.W., Cheon, S.O., Lee, H.P., Kim, H.T., Yoo, K.O.: A kinetic analysis of thermal degradation of polymers using a dynamic method. Polym Deg Stab 67, 535-540 (2000)

16. Gaoa, Z., Amasaki, I., Kanekoa, T., Nakada, M.: Calculation of activation energy from fraction of bonds broken for thermal degradation of polyethylene. Polym Deg Stab 81, 125-130 (2003)

17. Faravelli, T., Bozzano, G., Scassa, C., Perego, M., Fabini, S., Ranzi, E., Dente, M.: Gas product distribution from polyethylene pyrolysis. J Anal Appl Pyrol 2, 87-103 (1999)

18. Yanga, J., Mirandab, R., Roy, C.: Using the DTG curve getting method to determine the apparent kinetic parameters of thermal decomposition of polymers. Polym Deg Stab 73, 455-461 (2001)

19. Panda, A.K., Singh, R.K., Mishra, D.K.: Thermolysis of waste plastics to liquid fuel: a suitable method for plastic waste management and manufacture of value added products-A world prospective. Renew Sustain Energy Rev 14, 233-248 (2010)

20. Murata, K., Sato, K., Sakata, Y.: Effect of pressure on thermal degradation of polyethylene. J Anal Appl Pyrol 7, 569-589 (2004)

21. Faravelli, T., Pinciroli, M., Pisano, F., Bozzano, G., Dente, M., Ranzi, E.: Thermal degradation of polystyrene. J Anal Appl Pyrol 60, 103-121 (2001)

22. Sorum, L., Gronli, M.G., Hustad, J.E.: Pyrolysis characteristics and kinetics of municipal solid wastes. Fuel 80, 1217-1227 (2001) 